IBIMA Publishing

Journal of African Research in Business \& Technology

http://www.ibimapublishing.com/journals/JARBT/jarbt.html

Vol. 2014 (2014), Article ID 424779, 10 pages

DOI: $10.5171 / 2014.424779$

Research Article

\title{
The Acceptance of ICT by Geriatricians Reinforces the Value of Care for Seniors in Morocco
}

\author{
Az-Eddine Bennani ${ }^{1}$ and Rachid Oumlil ${ }^{2}$ \\ ${ }^{1}$ Reims Management School, Reims, France \\ ${ }^{1}$ Université de Technologie de Compiègne, Compiègne, France \\ ${ }^{2}$ University Ibn Zohr, Agadir, Morocco
}

Correspondence should be addressed to: Az-Eddine Bennani; Az-ddine.bennani@reims-ms.fr

Received date: 6 October 2013; Accepted date: 5 March 2014; Published date: 28 March 2014

Copyright (C) 2014. Az-Eddine Bennani and Rachid Oumlil. Distributed under Creative Commons CCBY 3.0

\begin{abstract}
Recently in Morocco, the geriatrics specialty has been officially recognized by the Ministry of health. However it is faced to many lacks of suitable facilities, technical and resources to meet the needs of Moroccan seniors. As a valuable technology, Information and Communication Technologies can contribute to solving this matter and create an innovative added value for both, elderly and geriatricians. But these are conditioned by the acceptance and the usage of ICT by geriatricians. Hence, this communication aims to identify factors supporting the acceptance of ICT by geriatricians in Morocco. The study was conducted in health public hospitals in Agadir city, South of Morocco. It revealed that only three factors, Compatibility, Perceived Usefulness, and Perceived Ease of Use seem to be significant for this acceptance.
\end{abstract}

Keywords: Information and Communication Technology, Technology Acceptance Model and its extensions, Value of care, Physicians practicing as Geriatricians, Elderly patients, Public healthcare hospitals in Morocco.

\section{Introduction}

Recently, a demographic shift characterized by a relative aging of the population has been noticed in Morocco. This phenomenon is likely to evolve over the coming decades. Also, the latest census of population shows that $8 \%$ of Moroccan population is elderly, which represents two million people. Moroccan National Center for Demographic
Studies projects an increase of this figure; it will double in the coming years to reach five million. "It is therefore "important to get prepared to help this category of population both socially and medically" said Dr Mustapha Oudrhiri, geriatrician and chairman of the Moroccan Association of Gerontology.

Cite this Article as: Az-Eddine Bennani and Rachid Oumlil (2014), "The Acceptance of ICT by Geriatricians reinforces the value of care for seniors in Morocco", Journal of African Research in Business \& Technology, Vol. 2014 (2014), Article ID 424779, DOI: 10.5171/2014. 424779 
In Morocco, geriatrics as a specialty has been officially recognized by the Ministry of Health during 2005. However, the promotion of this specialty remains below expectation. Indeed, according to this Ministry, only 16 physicians are currently practicing in full time as geriatricians in Moroccan hospitals, instead of 250 needed.Moreover, these specialists face a lack of suitable facilities and lack of technical and resources to meet the needs of Moroccan seniors. In the same way as other patients, these people get health services from physicians which are not geriatricians, even if their health problems differ greatly from the ones of young people.

As a valuable technology, Information and Communication Technology (ICT) can contribute to solving this matter and engender an added value for both, elderly and geriatricians.

If in ICT, value is closely related to its usages, in healthcare organizations, value is often defined as an economic contribution to expenses reduction (Scott, 2007). But it is also the improvement of the quality of delivered care (Wu et al. 2009) and quality of life (Alemdar and Ersoy, 2010).On this matter, Simon et al. (2007) noted that "Electronic Health Records (EHR) have great potential to improve quality and safety in healthcare... but these improvements will occur only if clinicians have access to key functions in EHR systems and use them regularly".

Referring to Davis (1989) a technology is used only if it is completely accepted by potential users. Thus, the acceptance of ICT by geriatricians as medical practitioners reinforces the value of care for elderly patients.

This communication aims to identify factors supporting ICT acceptance by physicians practicing geriatrics in Morocco. The study was conducted in health public hospitals in Agadir city, South of Morocco. Because of the insufficient of the number of geriatricians in this country as mentioned before, the study addresses physicians practicing as geriatricians even if they are not specialist in geriatrics.
The first paragraph will review the literature on the Technology Acceptance Model and its extensions. It will also present the research work on the acceptation of ICT in healthcare context. The second one will introduce the hypothesis and will describe the research model. The third will explain the methodology retained and will present results of this communication, followed by the conclusion and managerial implication in the last paragraph.

\section{Literature Revue}

The Technology Acceptance Model (TAM), originally proposed by Davis in 1986, presents a significant contribution to predict computer user acceptance. It was largely adopted by Information System community to understand behaviour of individuals towards Information and Communication Technology (Legris, 2003). Referring to Davis, Bagozzi and Warshaw (1989), Bertrand and Bouchard (2008) summarized that TAM was developed for three main reasons: (1) to identify factors explaining the computer acceptance in general; (2) to predict user behaviour as far as ICT concerned; and (3) to provide a parsimonious theoretical explanatory model. The following paragraph presents the Technology Acceptance Model and its significant extensions then highlights ICT acceptation in healthcare context.

\section{Technology Acceptance Model and its Extensions}

\section{Technology Acceptance Model}

The Technology Acceptance Model is established from reasoned action model and theory (Fishbein and Ajzen, 1975; Ajzen et Fishbein, 1980) to explain human behavior related to ICT acceptance (Davis etal, 1989). It assumes that the acceptance is determined by two major Constructs: Perceived Usefulness (PU) and Perceived Ease of Use (PEOU). The first construct (PU) is defined as the extent to which a person believes that using a technology would enhance her/his job performance and the second one, the PEOU is the extent to which a person believes that using a technology would be free of effort (Davis, 1989). The TAM postulates that the real use of a technology 
could be determined by Behavioral Intention. This later is directly influenced by both Attitude Toward Using and Perceived Usefulness, and indirectly by external variables through Perceived Usefulness and Perceived Ease Of Use.

Since 1989, to predict ICT acceptance, many studies applied TAM (Adams et al, 1992; Segars and Grover, 1993; Chin and Gopal, 1995; Giffen and Straub 1997) and considered it as a basis model (Igbaria et al, 1997). Moreover, other studies were limited on the validation of Perceived Usefulness and Perceived Ease of Use (Lucas and Spilter, 1999; Venkatesh and Morris, 2000), or the test of causal relations between Behavioral Intention, Actual Use, Perceived Usefulness, Perceived Ease of Use, Attitude Toward Using and External Variables (Davis et al, 1989; Taylor and Todd, 1995; Chau, 1996; Lucas and Spilter, 1999; Venkatesh and Morris; 2000 and Hong et al., 2002).

In spite of the contributions of TAM to predict ICT acceptance, Dillon and Morris (1996) noted the need for its extension.

\section{Extensions of Technology Acceptance Model}

For better prediction, the extension of the Technology Acceptance Model seems necessary. Its capacity to predict ICT acceptance by individuals can be improved only by considering some additional external variables (Agarwal and Prasad, 1999). Only three of them, the most important, were retained for the purpose of this communication.

Venkatech and Davis (2000) proposed the first extension. They noted the limitation of TAM to explain reasons for which a potential user perceived the usefulness of this model.Therefore, theyproposed an extended model call named TAM2. This new model integrated additional external factors as antecedents of Perceived Usefulness.These factors include: Subjective Norm, Image, Job Relevance, Output Quality and Result Demonstrability. Experience and Voluntariness wereincluded as moderating variables of Subjective Norm.
To evaluate the performance of their model, Venkatesh and Davis conducted a longitudinal study including two voluntary and mandatory environments. Their results revealed that Subjective Norm, Image, Job Relevance, and Result Demonstrability were significant factors influencing Perceived Usefulness. Moreover, they indicated that Subjective Norm, Perceived Usefulness and Perceived Ease of Use influenced directly Intention to use. Also, relationship between Output Quality and Job Relevance is shown to be significant, however, relationship between Subjective Norm, Experience and Voluntariness were not significant.Venkatesh and Davis concluded that TAM2 performed in both voluntary and mandatory environments with the exception that Subjective Norm had effect on mandatory setting but did not on involuntary setting.

The second important extension of TAM was introduced by Venkatesh (2000), who revisited the antecedents of PEOU. He identified two main groups of antecedents for PEOU: Anchors and Adjustments. Anchors were considered as general beliefs about computers and computer usage. They include four factors: Computer Self-Efficacy, Perception of External Control, Computer Anxiety and Computer Playfulness. Whereas adjustments were considered as beliefs that are shaped based on direct experience with target system, they are limited on two factors: Perceived Enjoyment and Objective Usability.

Empirically, Venkatesh has tested his model in three different organizations with 246 participants and three measurements taken over three month period. His results revealed in time one that Perceived Enjoyment and Objective Usability were not significant. However in time two, all antecedents of perceived Ease of Use were significant. Finally in time three, Computer Playfulness was not significant. To conclude, this model provides a strong support for variables in explaining PEOU for Information and Communication Technology.

The third and last extension was developed by Venkatesh, Morris, Davis and Davison 2003. The authors reviewed and compared eight models used to explain individual 
behavior toward ICT. These models included: Theory of Reasoned Action, Technology Acceptance Model, Motivational Model, Theory of Planned Behavior, a Combined Theory of Planned Behavior/Technology Acceptance Model, Model of Personal ComputerUtilization, Innovation Diffusion Theory and Social Cognitive Theory. They revealed five important limits of these models: (1) Simplicity of the technologies studied (2) except for a few studies, most participants were students (3) time of the measurement was in general after acceptance or rejection decisions (4) nature of measurement was in general cross-sectional and (5) most of studies were conducted in a voluntary usage setting. Therefore, they noticed the need for a synthesis to reach a unified view of user's technology acceptance. Furthermore, they developed the Unified Theory of Acceptance and Use of Technology (UTAUT) model to explain individual intentions to use an Information and Communication Technology and subsequent usage behavior. This model includes four core factors of intention and usage: (1) Performance Expectancy, (2) Effort Expectancy, (3) Social Influence, and (4) Facilitating Conditions. The variables of gender, age, experience and voluntariness of use moderate the key relationships. Besides, UTAUT attempts to explain how different individuals influence ICT use. Especially, how the relationship between perceived usefulness, ease of use, and intention to use can be moderated by age, gender, and experience.

Empirically the authors validated the UTAUT model among longitudinal studies conducted in four different organizations in various industries at three different points in time: post training, one month after implementation and three months after implementation.

Results showed that The UTAUT was able to account for 70 percent of the variance in usage intentions towards adopted technologies. Moreover four constructs (Performance Expectancy, Effort Expectancy, Social Influence, and Facilitating Conditions) are direct determinants of usage intention and behavior. Also, gender, age, experience, and voluntariness of use mediated the impact of the four key constructs on usage Intention and behavior.

\section{ICT Acceptation in Healthcare Context}

Technology Acceptance Model (Davis, 1989) is largely used by researchers to predict acceptance and use of technologies by the individuals in various contexts. Nevertheless, in healthcare context, the number of contributions still very limited (Aggelidis and Chatzoglou, 2009). The following subparagraph synthesis some applications and extensions of TAM in this context.

The massive investment on Information and Communication Technologies by healthcare organizations was the main reason that pushed $\mathrm{Hu}$, Chau, Sheng and Tam (1999) to study the acceptance of these technologies by physicians. They referred to the Theory of Reasoned Action, Theory of Planned Behavior and Technology Acceptance Model to explain the acceptance of the telemedicine by physicians. Their results confirmed that: Perceived Usefulness and Attitude influence significantly the Intention physicians to use telemedicine. They conclude that TAM seems to be able to provide a reasonable depiction of physicians.

In 2001, Handy, Hunter and Whiddett studied Electronic Medical Records (EMR) acceptance by physicians and midwives of a large urban hospital in New Zealand. Their results showed that EMR acceptance is determined by Perceived Usefulness and Perceived Ease of Use. But these authors concluded that TAM needs adjustment to predict the ICT acceptance in healthcare context.

As far as Chau and $\mathrm{Hu}$ (2002), they studied the acceptance of the telemedicine by physicians of public hospitals in HongKong. Their results revealed that Perceived Usefulness and Attitude are the most significant factors of telemedicine acceptance by physicians. However Perceived Ease of Use and Subjective Norm have no influence on this acceptance.

Furthermore, Harris, Donaldson and Campbell (2002) explored factors predicting acceptance of telemedicine by experts of care of the rural zones. Their results showed a strong correlation between "Organizational 
Support" and variables of the TAM and a weak correlation between "Age" and the variables of the TAM. The three authors concluded that, for a good prediction of telemedicine acceptance by healthcare experts, other moderating factors should be considered such as: Age, Organizational Support and Time.

Chismar and Patton (2002) studied the intention of pediatricians to accept internetbased applications. They carried out an adaptation of the TAM2 to the context of pediatricians, by eliminating two variables "Voluntariness" and "Experience". Results of their analysis showed that Perceived Usefulness influence positively the Intention of the pediatricians to accept internet-based applications, whereas Perceived Ease of Use, Social Influence and Image have no influence on this Intention. The Authors concluded that TAM2 is a relevant model to predict ICT acceptance in a healthcare context.

In 2007, authors Pynoo, Devolder, Voet, Vercruysse, Adang and Duyck referred to the TAM and the UTAUT to study the acceptance of Picture Archiving and Communication System (PACS) by the physicians and nurses. Results of this research indicated that, inside an obligatory context, the Attitude is the best factor to predict ICT Acceptance. Moreover, during the implementation process, factors: Perceived Usefulness and Perceived Ease of Use seem to be the most important determinants.

Another application of UTAUT to predict ICT acceptance in healthcare context is conducted by Kijsanayotin, Pannarunothai and Speedie(2009) research. The three authors studied factors that influence health ICT acceptance in community health centers in Thailand. Their results revealed that this acceptance is influenced by Performance Expectancy, Effort Expectancy, Social Influence and Voluntariness.Moreover, the use of health ICT is predicted by previous ICT experiences, intention to use the system, and facilitating conditions.

Furthermore, to predict ICT acceptance in healthcare context, other researchers did not limit their studies to a simple application of the TAM, TAM2 or UTAUT, but tend to introduce other additional variables to predict the ICT acceptance. For example, Croteau and Vieru (2002) introduced Situational Support, Perceived Confidence and Image to explain telemedicine acceptance by physicians. Moreover, $\mathrm{Wu}$ et al. (2007) introduced Technical Support and Training, Management Support, Compatibility, Computer Self-Efficacy to predict mobile healthcare acceptance. Besides, Banderker and Van Belle (2006) conducted a qualitative study in two public hospitals in Western Cape, South Africa, to study factors influencingmobile acceptance by physicians. They concluded that Work importance, Utility, Fit task-work, Demonstrability, Self-efficacy and Characteristics of the technology influence positively the intention of physicians to accept ICT. In 2006, Paré, Sicotte and Jacques integrated a new factor named psychological ownership to understand physician's acceptance of clinical information systems.

\section{Hypotheses and Research Model}

Two main issues were presented in the literature review on ICT acceptance by individuals. The first one states Technology Acceptance Model and its significant extensions, the second issue reviews various models predicting this acceptance in healthcare context. Furthermore, prior exploratorystudies (author et al., 2008, author et al., 2009, author and coauthor, 2010) helped to inspire the hypothetical research model suggested in this communication (Figure 1). 


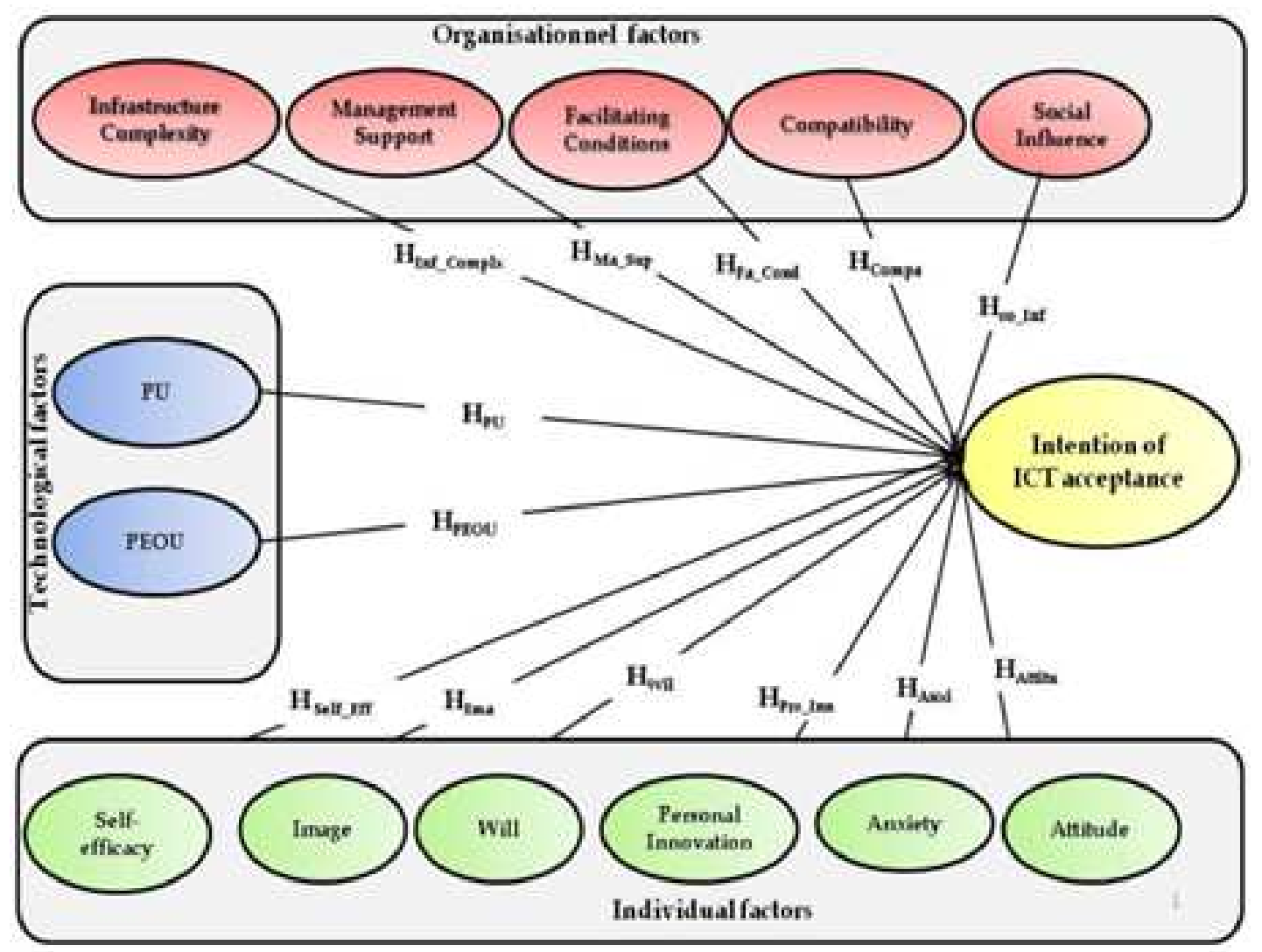

Figure 1: Hypothetical Research Model

This model posits that ICT acceptance is influenced by three categories of factors: Individual, Organizational and Technological. Hence, the statement of the main hypothesis: geriatricians' intention to accept ICT is influenced by individual beliefs, organizational structure and technological factors. It leads to three sets of hypothesis:

The first category concerns individual beliefs resulting in six factors that regulate behavior and emphasizes the influence of these factors for the acceptance of ICT by geriatricians:

- Helf_Eff: The Self-efficacy influences positively the intention of the ICT acceptance by geriatricians working in Moroccan health public hospitals;

- $\mathrm{H}_{\text {Anxi: }}$ The Anxiety influences negatively the intention of the ICT acceptance by geriatricians working in Moroccan health public hospitals;
- $\mathrm{H}_{\text {Ima: }}$ The Image influences positively the intention of the ICT acceptance by geriatricians working in Moroccan health public hospitals;

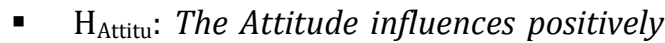
the intention of the ICT acceptance by geriatricians working in Moroccan health public hospitals;

- $\mathrm{H}_{\mathrm{Wil}}$ : The Will influences positively the intention of the ICT acceptance by geriatricians working in Moroccan health public hospitals; and,

- HPrsinn: The Personal Innovation influences positively the intention of the ICT acceptance by geriatricians working in Moroccan health public hospitals. 
The second category focuses on organizational structure expressed by five factors and presents the influence of these factors on the Intention of ICT acceptance by geriatricians:

- $\mathrm{H}_{\text {Compa: }}$ The Compatibility influences negatively the intention of the ICT acceptance by geriatricians working in Moroccan health public hospitals;

- $\mathrm{H}_{\mathrm{Fa} \text { Cond: }}$ The Facilitating Conditions influence positively the intention of the ICT acceptance by geriatricians working in Moroccan health public hospitals;

- Ho_Inf: The Social influences affect positively the intention of the ICT acceptance by geriatricians working in Moroccan health public hospitals;

- Ha_sup: The Managerial Support influences positively the intention of the ICT acceptance by geriatricians working in Moroccan health public hospitals; and,

- $\mathrm{H}_{\text {Inf_complx: The Infrastructure }}$ Complexity influences negatively the intention of the ICT acceptance by geriatricians working in Moroccan health public hospitals.

The third and the last category presents two technological factors and shows the influence of these ones on the Intention of acceptance by geriatricians:

- $\mathrm{H}_{\mathrm{Pu}}$ : The Perceived Usefulness influences positively the intention of the ICT acceptance by geriatricians working in health public hospitals; and,

- H Heou: The Perceived ease of use influences positively the intention of the ICT acceptance by geriatricians working in health public hospitals.

\section{Research Methodology and Results}

87 questionnaires were distributed to physicians practicing also geriatrics and who work in health public hospitals located in Agadir city. They promulgate care to young as well as elderlypeople.Only 51 responses have been received, representing a response rate of $58.62 \%$. More than half of respondents (52.9\%) aged between 25 and 40 years, whereas, $47.1 \%$ are older than 40 . Moreover $56.9 \%$ of those respondents are males and only $43.1 \%$ corresponded to females.

Furthermore the reliability of the hypothetical model constructs is checked using the Cronbach's coefficient $(\alpha)$. A very good coherence is shown between items of Attitude toward Using ( $\alpha=0.809)$, Anxiety $(\alpha=0.873)$, Image $(\alpha=0.835)$, Managerial Support $(\alpha=0.913)$, Perceived Usefulness $(\alpha=0865)$, Perceived Ease of Use $(\alpha=0.859)$ and Intention of the ICT acceptance $(\alpha=0.808)$.

Besides, a good coherence is noted only for Social influence with $\alpha=0.781$. An acceptable reliability is shown between items of SelfEfficacy (0.678) and those of Infrastructure Complexity (0.660). However, a week reliability is revealed for Will $(\alpha=0.102)$, Personal Innovation $(\alpha=-0.060)$ and Facilitating Conditions $(\alpha=0.394)$. 
Table 1: Correlation between Independent Variables and Intention of ICT Acceptance

\begin{tabular}{|c|c|c|c|c|c|c|c|c|c|}
\hline \multicolumn{2}{|c|}{} & Attit & Anxi & Ima & Compa & So_Infl & Ma_Sup & PEOU & PU \\
\hline \multirow{4}{*}{ Intention } & $\begin{array}{l}\text { Corrélation } \\
\text { de Pearson }\end{array}$ &, 284 &,- 289 &, $365^{*}$ &, $612^{* *}$ &, 117 &, $403^{* *}$ &, $419^{* *}$ &, $617^{* *}$ \\
\cline { 2 - 9 } & $\begin{array}{l}\text { Sig. } \\
\text { (bilatérale) }\end{array}$ &, 062 &, 064 &, 014 & 0,00 &, 451 &, 005 & 3,00 &, 000 \\
\cline { 2 - 10 } & $\mathbf{N}$ & 44 & 42 & 45 & 44 & 44 & 46 & 48 & 47 \\
\hline
\end{tabular}

Hence, only Attitude toward Using, Anxiety, Image, Managerial Support, Perceived Usefulness, Perceived Ease of Use, Social Influence and Intention of the ICT acceptance are retained for the following of the analysis, their reliability coefficient being higher than the recommended threshold (0.7).

To validate the research hypothesis, a correlation analysis is adopted. For this issue, the Pearson's coefficient was calculated between Intention of the ICT acceptance and each one of the retained variables. Results reveal that Image, Compatibility, Management Support, Perceived Usefulness and Perceived Ease of Use showed a significant positive correlation with this Intention (Table 1).Moreover linear regression results indicate $60.4 \%$ of total variance and show that only Compatibility, Perceived Usefulness and Perceived Ease of Use are the significant factors of the ICT acceptance by Geriatricians working in Moroccan health public hospitals

\section{Conclusion and management implication}

This communication aims to identify factors supporting ICT acceptance by geriatricians in Morocco. It shows that only three factors seem to be significant for this acceptance. The first one, Compatibility, involves adequacy of ICT to values and practices of geriatricians. The second, Perceived

Usefulness, posits the utility of these technologies for geriatricians to improve their administrative and healthcare tasks. The last factor, Perceived Ease of Use, notes the specificity of ICT to be used without mental effort. Those outcomes confirm the main hypothesis supposing that geriatricians' intention to accept ICT is influenced by individual beliefs, organizational structure and technological factors.

Finally, the proposed model could help healthcare managers to identify forces supporting acceptance and usage of ICT solutions by geriatricians, hence create value for the elderly patients.

\section{References}

1. Adams, D.A., R.R. Nelson, P.A., Todd, 1992. Perceives Usefulness, Ease of Use, and Usage of Information Technology: A Replication. MIS Quarterly. Vol. 16, No. 2, pp. 227-247

2. Agarwal, R., Prasad, J., 1999. Are Individual Differences Germane to the Acceptance of New Information Technologies?. Decision Sciences, Vol. 30, n² , pp. 361-391.

3. Aggelidis, V.P., Chatzoglou, P.D., 2009. Using a modified technology acceptance model in hospitals. International journal of medical informatics, 7 8, 115-126

4. Ajzen, I., Fishbein, M. (1980). Understanding attitudes and predicting social behaviour. Englewoon Cliffs, New Jersey: Prentice-Hall.

5. Alemdar, H., Ersoy, C., 2010. Wireless sensor networks for healthcare: A survey. Computer Networks.pp.1-23

6. Bertrand, M., Bouchard, S., 2008. Applying the technology acceptance model to vr with people who arefavorable to its use, Journal of Cyber Therapy \& Rehabilitation, vol1 (2), pp.200-210 
7. Chau, P.Y.K., 1996. An Empirical Investigation of Factors Affecting the Acceptance of CASE by Systems Developers. Information \& Management, Vol. 30, $\mathrm{n}^{\circ} 6$, pp.269-280.

8. Chau, P.Y.K. Hu, P.J. 2002. Investigating healthcare professionals' decisions to accept telemedicine technology: an empirical test of competing theories. Information \& Management 39 (4) pp.297-311.

9. Chin, W.W., Gopal, A., 1995. Adoption Intention in GSS: Relative Importance of Beliefs.DataBase, Vol. 26, n²-3, pp. 42-63.

10. Chismar, W.G., Wiley-Patton, S., 2003. Does the extended technology acceptance model applies to physicians. in: Proceedings of the 36th Hawaii International Congress on System Sciences, IEEE Computer Society, Big Island, Hawaii.

11. Croteau A-M., Vieru D. 2002. Telemedicine Adoption by Different Groups of Physicians, Proceedings of the 35th Hawaii International Conference on System Sciences

12. Davis, F.D., Bagozzi R., WarshawP.R., 1989. User acceptance of computer technology : a comparison of two theoretical models. Management Science, Vol. 35, № 8, August, pp. 982-1003

13. Davis, F. D., 1986. A technology acceptance model for empirically testing new end-userinformation systems: theory and results.Doctoral dissertation, Sloan School of Management, Massachusetts Institute of Technology.

14. Davis, F. D., 1989. Perceived usefulness, perceived ease of use, and user acceptance in information technology. MIS Quarterly, vol. 13 , no. 3 , pp. 319-340.

15. Dillon, A., Morris, M., 1996. User acceptance of information technology: theories and models. Journal of American Society for Information Science, vol. 31, no., pp. 3-32

16. Fishbein, M., Ajzen. I.,1975. Belief, Attitude, Intention and Behaviour: An Introduction to Theory and Research. Addison-Wesley, Reading, MA
17. Gefen, D., Straub, D.W., 1997. Gender Differences in the Perception and Use of Email : An Extension to the Technology Acceptance Model. MIS Quarterly, Vol.21, $\mathrm{N}^{\circ} 4$, pp. 389-400.

18. Handy, J., Hunter, I., Whiddett , R., 2001. User acceptance of inter-organizational electronic medical records. Health Informatics Journal, vol. 7: pp. 103 - 107.

19. Harris, K., Donaldson, J., and Campbell, J. (2001). "Introducing computer-based telemedicine in three rural Missouri counties", Journal of End User Computing, 13(4), pp.26-35.

20. Hong W., Thong J., Wong W.M., Tam K.Y., 2002. Determinants of user acceptance of digital libraries, Journal of Management Information System, Vol. 18, $\mathrm{N}^{\circ} 3$, Winter, pp. 97-124.

21. Hu, P.J. , Chau, P.Y.K., Liu Sheng, O.R., Tam, K.Y., 1999. Examining the technology acceptance model using physician acceptance of telemedicine technology. Journal of Management Information Systems 16 (2) pp.91-112.

22. Igbaria, M., Zinatelli, N., Cragg, P., Cavaye., A.L.M. (1997). "Personal Computing Acceptance Factors in Small Firms: A Structural Equation Model, MIS Quarterly, Vol.21, N³, pp. 279-305.

23. Kijsanayotin,B.,Pannarunothaib, S., Speediec, M-S., 2009. factors influencing health information technology adoption in Thailand's community health centers: Applying the UTAUT model, international journal of medical informatics. 7 8.pp. 404416

24. Legris, P., Ingham, J., Collerette, P., 2003. Why do people use information technology? A critical review of the technology acceptance model. Information \& Management, 40, pp.191-204

25. Lucas, H. C.J., Spitler, V.K., 1999. Technology Use and Performance: A Field Study of Broker Workstations. Decision Sciences, Vol. 30, N², pp. 291-311.

26. Paré, G., Sicotte, C., Jacques, H., 2006. The Effects of Creating Psychological Ownership 
on Physicians' Acceptance of Clinical Information Systems. Journal of the American Medical Informatics Association, Vol. 13 Number 2, pp.197-205.

27. Pynoo, B., Devolder, P., Voet, Vercruysse, J., Adang, L. et Duyck, P., 2007. Attitude as a Measure for Acceptance: Monitoring IS Implementation in a Hospital Setting. SIGHCI Proceedings. Paper 21.

28. Scott, R.E., 2007. E-Records in healthpreserving our future. International Journal of Medical Informatics 76. pp.427-431

29. Segars, A.H., Grover, V., 1993. Reexamining Perceived Ease of Use and Usefulness: A Confirmatory Factor Analysis, MIS Quarterly, Vol.17, N4, pp. 517-525.

30. Simon SR, Kaushal R, Cleary PD, Jenter CA, Volk LA, Orav EJ., 2007. Physicians and electronic health records: a statewide survey. Arch Intern Med;167:507-12.

31. Taylor, S., Todd, P., 1995. Assessing IT Usage: The Role of Prior Experience. MISOuarterly, December, pp.561-570.

32. Taylor, S., P. A. Todd. 1995. Understanding information technology usage: A test of competing models. InformationSystems Research. 6, pp.144-176

33. Venkatesh, V., 2000. Determinants of Perceived Ease of Use: Integrating Perceived 39.
Behavioral Control, Computer Anxiety and Enjoyment into the Technology Acceptance Model, Information Systems Research (11:4), pp. 342-365.

34. Venkatesh, V., Morris. M.G., 2000. Why don't men ever stop to ask for directions? Gender, social influence, and their role in technology acceptance and usage behavior. MIS Quarterly, 24(1), pp.115-139.

35. Venkatesh, V., Davis, F.D., 2000. A theoretical extension of the technology acceptance model:four longitudinal field studies. Management Science, 46, pp.186204.

36. Venkatesh, V., Morris, M.G., Davis, G.B., Davis, F.D., 2003. User acceptance of information technology: Toward a unified view.MIS Quarterly, Vol. 27 No. 3, September, pp. 425-478.

37. $\mathrm{Wu}, \mathrm{J}-\mathrm{H} .$, Chenc, Y-C., Greenese, R.A., 2009. Healthcare technology management competency and its impacts on IThealthcare partnerships development.International Journal of Medical Informatics. (7 8) pp.71-82.

38. Wu, J-H., Wang,S-C., Lin, L-M., 2007. Mobile computing acceptance factors in the healthcare industry: A structural equation model. International journal of medical $\begin{array}{llll}\text { informatics } & 7 & 6 & \text { pp.66-77. }\end{array}$ 